(C)2017, Elsevier. Licensed under the Creative Commons AttributionNonCommercial-NoDerivatives 4.0 International http://creativecommons.org/ about/downloads 


\section{Being in Control? A Thematic Content Analysis of Interviews with}

\section{2,4-Dinitrophenol Users}

Neha Prasad Ainsworth* (corresponding author)

Kingston University, Penrhyn Road, Kingston-Upon-Thames, Surrey, KT1 2EE

Email Address: k1545825@kingston.ac.uk

Elisabeth Julie Vargo

Kingston University, Penrhyn Road, Kingston-Upon-Thames, Surrey, KT1 2EE

Andrea Petróczi

Kingston University, Penrhyn Road, Kingston-Upon-Thames, Surrey, KT1 2EE 


\section{Being in Control? A Thematic Content Analysis of 14 In-Depth Interviews with 2,4- Dinitrophenol Users}

\section{Abstract}

Background: 2,4-Dinitrophenol (2,4-DNP) is a compound with multiple industrial purposes. Currently unlicensed for human consumption, it is used by the gym-going population for drastic, short-term body fat loss. Nonetheless, physiological mechanisms can lead to potentially fatal hyperthermia. Reported fatal incidents have caused concern and highlighted the need for intervention. Understanding decision-making leading to 2,4-DNP use alongside the perceived outgroup attitudes is vital to forming effective harm minimisation policies targeting current and potential users. First-hand accounts from this elusive population are scarce.

Methods: Fourteen novel and experienced users (13 male, 1 female) were recruited via "snowballing" techniques. Semi-structured interviews were conducted, comprising 28 questions. Thematic content analysis was conducted using 37 codes.

Results: Four characteristic themes emerged: 1. Users considered the Internet to be a crucial multifunctional resource directly impacting their 2,4-DNP use. 2. Users "respected" 2,4-DNP, proactively taking harm reduction measures. 3. Attitudinal polarisation towards 2,4 DNP within the gym-going community was consistent in all accounts. 4. Users perceived outgroup populations to have inherently negative attitudes towards their use. These themes fell under the all-encompassing theme of "being in control".

Conclusion: For the first time, this study offers a rich detail of attitudes toward 2,4-DNP use by giving a collective voice to users. The element of control over every aspect of the users' life appears to be a significant contributor to the successful risk-management of 2,4-DNP use. In the absence of an established safe upper limit and effective regulatory control, education is critical to harm minimisation.

Keywords: 2,4-DNP; Bodybuilding; Fat-burner; Sport; Qualitative; Athlete 
The use of performance enhancing drugs (PEDs) among bodybuilders around the world has been abundantly discussed in literature (Abrahin, de Sousa, \& Santos, 2014; Perry, Lund, Deninger, Kutscher, \& Schneider, 2005; Sepehri, Mousavi Fard, \& Sepehri, 2009; Nakhaee, Pakravan, \& Nakhaee, 2013; Sagoe, Andreassen, \& Pallesen, 2014). Based on self-reported surveys, prevalence rates for PED use among gym users ranges between 0.4\% to 35\% (Abrahin et al., 2014; Hitti, Melki, \& Mufarrij, 2014; Khullar, Scull, Deeny, \& Hamdan, 2016; Lazuras et al., 2017; Molero, Bakshi, \& Gripenberg, 2017; Sagoe, Molde, Andreassen, Torsheim, \& Pallesen, 2014; Simon, Striegel, Aust, Dietz, \& Ulrich, 2006; Striegel et al., 2006; Stubbe, Chorus, Frank, Hon, \& Heijden, 2014). Within this range, PEDs prevalence figures vary widely across substance types, timeframe and methods used to establish prevalence. Specifically, much focus has been on anabolic steroid use. Direct questioning methods typically yield a lower and more likely prevalence rate compared to indirect methods.

Uncertainty about the true prevalence rate aside, information concerning use patterns in this community is still limited, due to the attached societal stigma. The bodybuilding community appears to hide their substance use, and distorted perceptions are predominant in the general population (Evans, 2004; Gonzalez, McLachlan, \& Keaney, 2001). PEDs known to be generally used by bodybuilders are anabolic-androgenic steroids (AAS) (Kicman, 2008; Reardon \& Creado, 2014; Sagoe, Molde, Andreassen, Torsheim, \& Pallesen, 2014) and peptides such as human growth hormone (Meinhardt et al., 2010). Fat burners are also used, to create a larger caloric deficit for fat loss (Jeukendrup \& Randell, 2011), either through appetite suppression, direct effects upon users' metabolism, or both. However, one compound that has flitted in and out of use is 2,4-dinitrophenol (2,4-DNP).

\section{Overview of the Compound}

2,4-DNP is a member of the dinitrophenol chemical family. These chemicals have a wide variety of industrial applications (Harris \& Cocoran, 1995). 2,4-DNP raised interest upon discovering that ingestion caused significant weight loss (Harris \& Cocoran, 1995) and 
consequently, the compound was prescribed as a weight loss aid (Hardgrove \& Stem, 1938; Harris \& Cocoran, 1995; Horner, 1942; Parascandola, 1974). Between 1933 and 1935, an estimated 100,000 patients were given 2,4-DNP (Tainter, Stockton \& Cutting, 1935). Studies concerning human oral exposure comprise primarily of case reports and clinical studies dating between 1932 and 1938 (Harris \& Cocoran, 1995). These studies frequently had limitations as human trials did not include participant matched control groups (Harris \& Cocoran, 1995). This has created difficulty in separating side effects caused by 2,4 -DNP to potential pre-existing conditions of participants. Reliable accounts of 2,4-DNP's effects on humans thus lack in current literature.

2,4-DNP works through a variety of dose-dependent physiological mechanisms. Alongside being an uncoupler of oxidative phosphorylation, 2,4-DNP is also a chemical ionophore (Grundlingh, Dargan, El-Zanfaly, \& Wood, 2011). The resulting proton electrochemical gradient shift from this process means this potential energy dissipates as excess heat, rather than ATP conversion (; Grundlingh et al., 2011; Wallace \& Starkov, 2000). At high doses, ingesting the compound results in an elevated body temperature alongside increased caloric expenditure, leading to fat loss. Possible side effects also include hyperthermia, tachycardia, skin discolouration or rash (if allergic), nausea or vomiting, abdominal pain, agitation and headache, excessive sweating potentially resulting in electrolyte imbalances (Kamour et al., 2015). Some studies have suggested long term risks relating to peripheral neuropathy (Phillips \& Singer, 2013). Moreover, others have suggested the possibility of cataract formation from prolonged exposure (Allen \& Benson, 1935; Boardman, 1935; Kniskern, 1935; Lazar, 1935). However, mechanisms remain unclear and potential harms - apart from media reports of fatalities - are relatively unknown.

In addition to the level of acute health risks, there is a distinct differentiation between 2,4-DNP and AAS regarding effort. Because of its mechanism of action, 2,4-DNP use may appear as a shortcut for weight loss compared to dietary adherence. Notably, 2,4-DNP use has acute effect on lifestyle and wellbeing. Despite this, it is still considered less effort to use 2,4-DNP compared to AAS. This will be discussed in further detail later on. 
Currently, 2,4-DNP is not licensed for human consumption globally. No therapeutic dosage and duration, or safe upper limit, is established. Despite this, users are not dissuaded from using 2,4-DNP for fat burning purposes, and can easily access it from online sources.

\section{Method of Use}

The route of administration of 2,4-DNP is oral, taken either as tablets or capsules, once or twice a day. Based on users' online accounts and self-reports, 2,4-DNP appears to be commonly used in cycles (McVeigh et al., 2016; McVeigh, Germaine, \& Van Hout, 2016; Petróczi et al., 2015). Most 2,4-DNP cycles are brief - lasting anywhere from one to four weeks, but rarely longer (McVeigh et al., 2016). Typically, 2,4-DNP cycles are variable and dependent on a number of factors, both internal (i.e., bodyweight) and external (i.e., weather conditions). Users will often determine the ideal dosage solely through their bodyweight, not factoring in external determinants.

\section{Accessibility and Motives for Use}

Sale of 2,4-DNP for human consumption is presently illegal in the UK due to health concerns ("Warnings issued over deadly DNP 'diet drug', 2013; '“FSA action over DNP 'fat burner substances”', 2013; “New warnings issued over deadly DNP 'diet drug”', 2014). Consequently, users now take advantage of its easy accessibility via the Internet (McVeigh et al., 2016; Petróczi et al., 2015). An additional challenge is the ease with which 2,4-DNP can be obtained; as long as it is advertised "not to be used for human consumption", 2,4DNP can be sold without limitations (Petróczi et al., 2015). Compounding the issue are discussion boards, which users utilise to seek guidance and share experiences (Barratt, 2011). These factors counterbalance efforts of regulatory bodies to prevent access and use of 2,4-DNP.

2,4-DNP appears to be utilised by the gym-going population owing to its unique muscle-sparing properties (Goldgof et al., 2014). The existing limited literature suggests that motives for using 2,4-DNP are primarily tied to the short-term aesthetic goal of losing considerable amounts of body fat (McVeigh et al., 2016; Petróczi et al., 2015). Similar 


\section{RUNNING HEAD: QUALITATIVE ENQUIRY OF 2,4-DINITROPHENOL USE}

motives were found amongst young non-exerciser adults in hypothetical situations; those who wished to rapidly lose a considerable amount of weight were the most willing to take the risk with 2,4-DNP (Hoxha \& Petróczi, 2015).

Studies exploring prevalence and the experiences of users with regards to motives, reasons and risk perceptions associated with 2,4-DNP use are inadequate or non-existent. To date, research has evidenced that 2,4-DNP users make self-perceived conscious and informed decisions about 2,4-DNP and are well-prepared for the side effects (McVeigh et al., 2016; Petróczi et al., 2015;). Willingness to take risks with 2,4-DNP has been linked to body image and magnitude of the desired weight or fat loss (Hoxha \& Petróczi, 2015; Petróczi et al., 2015). However, studies investigating this matter are limited. There appears to be a clear gap in knowledge and disconnect between 2,4-DNP users and the scientific community researching voluntary 2,4-DNP use.

\section{Aims and Objectives}

Whilst prevention via warnings about the danger of 2,4-DNP could be an effective strategy for the naïve potential users, this approach is unlikely to deter those who are knowledgeable and experienced PED users. Prevention via controlling the supply has deemed difficult because of the widespread availability of the drug through the Internet. Where deterrence and control fail, there is room and need for strategies that primarily aims at harm-reduction. In order to explore 2,4-DNP use and implement harm reduction measures for this population, further evidence-based information is required. Though some understanding of the physiological effects of 2,4-DNP are evidenced through case reports and animal model experiments, very little is uncovered regarding psychological factors. Due to 2,4-DNP use being considered high risk and potentially dangerous behaviour even within the gym-going population, users tend to be very cautious when disclosing their 2,4-DNP use. As such, they are a hard-to-reach population, resulting in studies harvesting data from the Internet forums and discussion boards (e.g., McVeigh et al., 2016). 


\section{RUNNING HEAD: QUALITATIVE ENQUIRY OF 2,4-DINITROPHENOL USE}

A better understanding of this population can be reached by examining attitudes and subjective experiences with 2,4-DNP of the users. This study, for the first time, set out to provide a more thorough and comprehensive qualitative overview of users' experiences through thematic content analysis of semi-structured interviews. In particular, we aimed to explore 2,4-DNP users' attitudes towards the Internet as a tool, perceived attitudes of ingroups and out-groups towards their 2,4-DNP use, as well as exploring 2,4-DNP use through participants' attitudes towards the compound. This, in turn, can inform practically relevant and meaningful harm-reduction policies which are accepted by this population.

\section{Methods}

\section{Participant recruitment}

Recruitment consisted of a purposive sampling strategy carried out online.

"Snowballing", the recruitment of participants from a hidden population through peer referral (Biernacki \& Waldorf, 1981) procedures were utilised. This involved making initial contact with "gatekeepers" of various bodybuilding forums discussing 2,4-DNP use to gain better access to potential participants. The researcher was active in these forums and familiarised with their administrators. Discussing the study with gatekeepers helped credibility and made recruitment far easier than having approached individuals directly. Online recruiting from this population was challenging; the main reasons being the sensitive nature of discussing such compounds and a perceived lack of anonymity.

Specific exclusion/inclusion criteria for participants were being over 18 years of age and having previously done, or were currently doing, a 2,4-DNP cycle. Credibility of participants' accounts was individually judged by the level and accuracy of the specific details and information by which they described their experiences with 2,4-DNP (Gergen \& Gergen, 2000). 


\section{RUNNING HEAD: QUALITATIVE ENQUIRY OF 2,4-DINITROPHENOL USE}

Utmost care was taken to ensure participants' confidentiality, and this was emphasised when discussing the details of the study. Self-assigned alphanumerical codes were used for transcription and data analysis to maintain confidentiality and anonymity. Ethical approval was granted for the project by the Research Ethics Committee of the Faculty of Science, Engineering and Computing, Kingston University. Informed consent, voluntary participation, confidentiality and right to withdraw at any time from the study were all discussed with participants pre-interview, alongside any other queries.

\section{Measures: semi-structured interviews}

Semi-structured interviews were employed. The interview consisted of 28 questions (Appendix A), which were created by the research team and explored motivations, reasons, expectations, side effects, use of other drugs, knowledge of 2,4-DNP, peers and purchase. Interviews were designed to facilitate adequate dialogue between the interviewer and participant. Capitalising on the researcher having an in-depth understanding of the environment and surrounding culture, open questions were used as much as possible. Where possible, the interviewer asked the participant to expand upon answers in order to gather more information.

All interviews were conducted via Skype (v. 7.21.0.100 through to v.7.27.0.101) as participants resided in different parts of the world. Audio-only calls were used to ensure anonymity. Due to the stigmatisation of the compound even within gym communities, and its worldwide illegality concerning human consumption, we considered it prudent to utilise audio-only interviews. The locations of participants around the world meant that in person interviews were not possible. Interviews were recorded using a recording app (Audio Recorder, Android Open Source Project) on a smart phone (Samsung Galaxy S5) and uploaded to a password-protected computer.

\section{Data analysis:}




\section{RUNNING HEAD: QUALITATIVE ENQUIRY OF 2,4-DINITROPHENOL USE}

Transcription was conducted by the researcher (NPA) with the aid of an online transcription application (https://transcribe.wreally.com/). All identifying information was redacted from transcripts.

A thematic content analysis approach was employed to analyse the data (Braun \& Clarke, 2006). Due to the nature of the study, a deductive approach was used. This approach fit the methodology best to form themes driven by our theoretical interests in the area. A closed coding scheme was utilised; codes were determined pre-hoc and revised with the research team during analysis. Coding was conducted individually, then compared with the group of researchers to ensure consistency (Weber, 1990). The finalised codebook consisted of 37 codes (Appendix B). Clearly defined definitions of each code were constructed, and every effort was made to ensure consistency during the coding process. Atlas.ti (v.7.1.50) software was used for coding and analysis.

The process of theme formation was conducted by aggregating codes which we considered semantically similar, or which revolved around a similar facet present within the data. Thematic formation was conducted through a number of ways; firstly, frequency counts were analysed to determine if any codes had a large count (grounded), or were connected to other codes. Additionally, codes were pre-grouped into sub-themes before coding commenced. These sub-themes were further organised into over-arching themes, which could be applied to our dataset as a whole (Braun \& Clarke, 2006).

The process of thematic analysis (Braun \& Clarke, 2006) was organized in a clear framework that assisted researchers during the analytical step of this study. Throughout the process, in order to maintain the flexibility afforded by this methodology, codes were revised where necessary. This included post-hoc codification of text segments. Constantly checking over data, and recoding and rechecking the transcripts enabled the researchers to increase reliability of the codebook.

\section{Results}

\section{Participant sample demographics}




\section{RUNNING HEAD: QUALITATIVE ENQUIRY OF 2,4-DINITROPHENOL USE}

The final sample for the semi-structured interviews consisted of 14 participants (13 males and 1 female). The median age was 22 years old (age range of 19-39 years old). All but one participant were aged below 30 years old, with the remaining participant being over 30 years old. Self-reported ethnic origin breakdowns were as follows: 10 were White/Caucasian, one was Asian (Oriental), one was Asian (Indian, Pakistani, or Bangladeshi), one was Hispanic or Latino and one was mixed. With regards to locality, 11 resided in the USA, one in Canada, one in Germany and one in the Netherlands. All participants considered themselves regular gym goers.

Thirteen participants had used some form of PED or were currently using PEDs, with the remaining participant having no history of other PED use. Most participants had used recreational drugs previously (such as alcohol or marijuana). During their 2,4-DNP cycles, only one drank alcohol and two used marijuana. The rest did not use recreational drugs on cycle. Nine participants concurrently used other PEDs on their 2,4-DNP cycles. Participants' accounts regarding side effects and dosages were consistent with other reports of 2,4-DNP use.

\section{Emerging themes}

Thematic analysis revealed four core themes: (1) attitudes towards the Internet as a tool ("The world at your fingertips"), (2) non-participant societal and close peer group attitudes towards 2,4-DNP use ("What they would know about the horror stories"), (3) attitudes of the gym-going community ("There's two extremes...") and (4) participant attitudes towards 2,4-DNP ("I have to respect the hell out of this supplement"). These four core themes are related to each other through varying degrees, encapsulated in the overarching theme of "being in control" (as shown in Figure 1) and are vital in understanding 2,4-DNP users' experiences. The following sections are organised into the aforementioned overarching themes and further described through key concepts which emerged from analysis.

[INSERT FIGURE 1 HERE] 


\section{Attitudes towards the internet as a tool ("The world at your fingertips...")}

For our group of participants, the Internet was a vital tool. Not only did our participants have access to the vast array of information related to 2,4-DNP, they were also able to share experiences with other peers using the drug. By bringing such a variety of shared experiences and knowledge sources, one participant described it as "the world at your fingertips" (Male, the Netherlands).

The secrecy within these communities can make it difficult to obtain information and even 2,4-DNP sources. However, some participants had doubts regarding advice given over the Internet:

“...you're getting all this information not from a medical doctor, you know, from a bunch of dudes on the internet. And as much as it sounded like enough people have used it and put in the time and collectively pooled their experiences and stories that gave me a good base, it's still always a thought in the back of my mind because you know, I don't know how my body personally will respond to this, even though I'm just taking the one dose, I have no idea..." (Male, USA).

This excerpt hints at the risk present not only through ingesting 2,4-DNP, but also through taking advice from this online community. The wide accessibility of the Internet meant anyone could potentially offer advice, whether it is correct and safe or not. Some participants consequently had to be careful sifting the "broscience" (commonly accepted term in the community for non-scientifically based information) from the science; "One thing I had to learn to do not just with DNP but with uh, steroids as well is to filter the information and take everything with a grain of salt to learn what is considered I guess you can say broscience or you know, things that people discuss and not really have scientific backing for? versus reliable anecdotal evidence just because there isn't too much scientific evidence on a lot of these products that we're using. So lots and lots of research and lots and lots of digging through mud I guess you could say, to make sure that the information I had was more or less reliable." (Male, Canada). 


\section{RUNNING HEAD: QUALITATIVE ENQUIRY OF 2,4-DINITROPHENOL USE}

In short, our participants acknowledged the power of the Internet as a rich source of information. There was awareness that getting information from anonymous sources on the Internet was risky, and consequently participants were cautious when using it. Peer experiences were considered vital, despite the need for careful interpretation.

Perceptions of societal and close peer group attitudes towards 2,4-DNP use ("What they would know about the horror stories")

Within this section, participants' perceptions of society, friends and family's attitudes towards 2,4-DNP use are discussed separately. An important distinction between personal attitudes and outgroup's attitudes emerged strongly from the interviews. Both society's and social groups' attitudes towards 2,4-DNP were thought to be shaped by media reports of fatal cases. A further differentiation within friends dependent on their inclusion or exclusion from the gym-going community was also evident.

Perceived perceptions of society towards 2,4-DNP use

In 2015 , there was notable international media attention for the death of a young woman from a 2,4-DNP overdose (Morris, 2015). Many participants thought it to have had a significant impact on 2,4-DNP use perception by non-PED using outgroups;

"I imagine the average person we'd run into on the street, if they knew about DNP at all, what they would know about is the horror stories that, you know, come on the new... And, you know, their judgement of me using DNP would then be based on that, you know, very, very biased, very case-specific um, information." (Male, the Netherlands).

The use of the word "biased" implies that the public has a one-sided opinion, and this was a viewpoint shared by the whole cohort. When explaining why outgroups would consider 2,4-DNP negatively, participants commented on "laypeople" relying on news reports and superficial information;

“...you know, people fear what they don't understand and you know, perhaps rightfully so. But if people would do a little bit of research, before they give their opinions, I 


\section{RUNNING HEAD: QUALITATIVE ENQUIRY OF 2,4-DINITROPHENOL USE}

think we wouldn't have as much of an issue with it... I think the lack of education about DNP um, and all the other PEDs just causes issues you know. If people know how it worked, there wouldn't be a huge issue with it. It would just be, 'let's make sure you do it safely'. But you know, that's not how it is right now." (Male, USA).

Interestingly enough, some participants thought this negative viewpoint to be beneficial; "the last thing we need is more people that have no idea what they're doing, getting a hold of it and killing themselves with it. It's a dangerous compound, you know." (Male, USA). Several participants drew parallels between 2,4-DNP use and AAS use, saying 2,4-DNP use has a "very similar vibe as steroids have, where you hear about only the bad things that can happen and you never look at all the benefits." (Male, USA). AAS use is often associated with an aesthetic extreme of large amounts of muscle mass and consequently seen as an aesthetic outlier.

When discussing whether this attitude would change in the future, one participant was optimistic regarding future perceptions of 2,4-DNP: "I think at least, based on America, [laughs], everyone here is looking for that magic skinny pill that helps you lose weight..." (Male, USA). Weight loss is a relatable goal for the majority of the general public, as it fits with the "traditional" societal norms of beauty, particularly in Western societies.

The idea of an uninformed public is clear through these excerpts; the public is perceived as having "no idea" regarding what they are doing, alongside making hasty judgements based on a prominent media story. An ingroup/outgroup divide emerges from the data. This could account for the secrecy which surrounds the community, and could impact help-seeking behaviours.

Perceived attitudes of friends and protecting self-image

In general, participants were hesitant to inform their social networks of their 2,4-DNP cycles. It was perceived that naïve individuals held biased views towards this practice and only ingroup members could have an informed and valid opinion. 
Participants sometimes divided their friend groups into "bodybuilding friends" and "non-bodybuilding friends". This was crucial in their eyes; related to the earlier concept of the "layperson's" lack of education and misconceptions. One participant said "...didn't want them to uh, think that I was some crazy drug addict either because if my friends outside the bodybuilding community heard that I was using this performance enhancing drug, I think their initial reaction would be 'oh my gosh you are doing drugs, that's bad' and I did not want them to think that at all." (Female, USA). Fundamentally, participants viewed only ingroup gym-goers as trustworthy in relation to the accuracy of their opinions of 2,4-DNP. They were very concerned of outgroup's prejudices and negative opinions of drug use, and how they could potentially be damaged by negative stereotypes.

Protecting the family

The decision whether to tell friends and family about drug use can be difficult. Our cohort feared closure and non-acceptance, particularly with family. Those who kept their use away from family had various justifications for not informing them of their 2,4-DNP use, with one stating "what they don't know won't hurt them.” (Female, USA). One participant elaborates on his decision to tell some of his friends and family:

"I'm pretty open about my PED use so it was something that, um, most of my friends were kind of interested in when they found out. You know, I have done a good job of explaining stuff to people so um, I didn't have any problem telling most of them. I kept it on the down low for the most part cos of... my parents, cos they weren't huge fans of it. But everyone else I was pretty open with. And, um, you know, it was a good experience from that too, I had other people that'd, you know, if something were to go wrong, they would know about it at least...it wouldn't be a whole bunch of people wondering what happened." (Male, USA).

This particular individual's reasoning for informing his friends and family stemmed partly from a safety perspective. The usage of the word "at least" indicates that this was a minimum requirement for them, made on a personal level. Informing a small group of people for safety reasons was suggested as good practice. 


\section{Perceived attitudes of the gym-going community ("There's two extremes...")}

Participants almost universally acknowledged that there was growing interest within the gym-going community for 2,4-DNP use; some individuals were more "open" to its use, whilst others considered it to be wholly dangerous and unnecessary to any fat-loss goals individuals might have:

“... as with many things, there's two extremes: people who are very much for it you know, who supported using and people who you know, call it 'The Devil' and say no, you should never use it. And there's people in between..." (Male, the Netherlands).

Some participants offered potential reasons why some individuals in the gym-going population might disapprove of 2,4-DNP use; “...a lot of people don't like that there is this pill that you can take which causes you to lose fat" (Male, Canada). These people believe that there is an extremely high possibility of abuse. 2,4-DNP is viewed negatively because it is seen as a "no effort" pathway to reaching weight loss goals. 2,4-DNP is considered different to other PEDs: with other PEDs, the general understanding is that you still have to work hard and be consistent, whereas with 2,4-DNP, "you take it and it works" (Male, Canada), implying training and diet are not needed.

\section{Participant attitudes towards 2,4-DNP ("I have to respect the hell out of this supplement")}

Our participants were almost overwhelmingly positive about their use of 2,4-DNP, although they emphasised the need to "respect" the compound due to the potential adverse effects, alongside its lethality at certain doses;

"Right, my opinion is that it can be used very safely, and very effectively, to get great results, in a short period of time. But, the other side of the coin that, the other side of the coin is, you know, this is a fact, is that it is lethal at a certain dosage you know. There is all these adverse effects you know, such as the cataracts, it messing with you, with your thyroids, your metabolism, all these different things. It can adversely affect you that way. I think if you 


\section{RUNNING HEAD: QUALITATIVE ENQUIRY OF 2,4-DINITROPHENOL USE}

know what you're doing, and you do it properly, it can be used very safely and very effectively." (Male, the Netherlands).

For other participants, similar themes of respect and "doing it properly" were notable. it is crucial that underlying attitudes towards $2,4-$ DNP are "... based on the foundation of "I have to respect the hell out of this supplement' and I can't ever get out of turning into this mindset of getting impatient or taking more is better." (Male, USA).

According to another participant, the "wrong way" can lead to consequences "as severe as, you know, death. Or you know, having to deal with PN [peripheral neuropathy] symptoms for a long time or developing cataracts" if you do it the "wrong way". (Male, USA)

Most acknowledged that high doses were dangerous and condemned individuals taking high risks;

“...they're running a gram a day and I think that's reckless and asking for something to go terribly wrong. I believe the half-life is somewhere around $36 \mathrm{~h}$, so I mean there's no way to get it out of your body other than waiting. And if you gotta wait $36 \mathrm{~h}$ for half of it to get metabolised, there's nothing you're gonna be able to do to keep yourself alive and your body just starts cooking..." (Male, USA).

Upon further elaboration, when asked if they would ever push the boundaries with dosages, almost every participant said no. One went so far as to state that "it'd be a... one time experience thing [laughs]..." (Male, USA). Another stated:

"Not in a million years. For me...there's really no need, why risk messing up my body, you know. It's a marathon, not a sprint." (Male, USA).

In contrast, our participants strongly advocated for harm reduction measures as being the "right way" to approach using 2,4-DNP. One participant stated the importance of implementing “...due diligence and background, getting the blood work you need, taking the supplements and cycle support you need." (Male, USA).

When asked if they would recommend 2,4-DNP to anyone else, there was a definite polarisation. Some stated they would recommend it, provided certain conditions were met 
"I would definitely recommend DNP to people given that I have sufficient background with them. Erm, for someone for example online as I do most of my discussions online, I would not recommend it freely just because, I would give my opinion on it but I wouldn't actually tell them whether or not they should do it." (Male, Canada).

However, others went so far in the other direction;

"I would not recommend DNP to my worst enemy. It is, in my mind, it is a poison as well, I take it because I want the results. I do, if somebody told me they were taking it, as long as they've done their research, I will wholeheartedly support them. But I would never recommend it to somebody. I'd rather them find out about it on their own, do their own research and fully understand and grasp what DNP can do, what potential side effects are, what you can really gain from it before attempting it. And I would never, I would never supply it to anybody, I would never recommend it." (Male, USA).

Our cohort considered themselves to have a strong respect for the compounds, grown out of the research they had conducted before using 2,4-DNP. Most participants strongly advocated for individual research before embarking on a 2,4-DNP cycle and implementation of harm reduction measures. Polarised attitudes towards recommending 2,4DNP could be, in part, due to its lethality and severity of potential adverse effects.

\section{Discussion}

Our results give a number of novel insights regarding how 2,4-DNP users approach their use, as well as how perceived public perceptions influence their behaviour. It is clear that the majority of users get their information almost exclusively from the Internet. Users consider themselves well-educated on the risks and effects of 2,4-DNP, with most having done what they considered to be extensive research before embarking upon a cycle.

The four themes can be viewed through the overarching thematic lens of control, present to some degree in all the sub-themes discussed. It was clear how important the Internet was with regards to users' 2,4-DNP experiences. Users turned to the Internet for a number of purposes; from sourcing 2,4-DNP, to researching the compound and cycle details, as well as peer-to-peer experience sharing. In this sense, it was considered a 


\section{RUNNING HEAD: QUALITATIVE ENQUIRY OF 2,4-DINITROPHENOL USE}

powerful tool that allowed the sample to exert control over this risky practice. In particular, the Internet enabled users to exhibit greater control over their 2,4-DNP experiences in the following ways:

Firstly, the anonymity the Internet can provide was considered a valuable asset. Users can choose to be as anonymous or identifiable as they wished. There are a number of methods used to research and obtain 2,4-DNP which leave no trace. With regards to PEDs in general and the stigma attached to them, anonymity is extremely important for users. Many stated they did not want friends or family to know, due to the surrounding negative attitudes.

Secondly, the wide variety of PED-related information available via the Internet makes it a powerful tool for research. For example, several participants were able to find research papers about 2,4-DNP use effects on humans, increasing their knowledge on the compound's effects. Additionally, users could get anecdotal information from specific forums. Users were able to control which of these sources of information they utilised, based on their level of knowledge and trust in the information source.

Thirdly, participants had a wide variety of suppliers and vendors from which to choose. Different suppliers provide different dosages per capsule, types of 2,4-DNP (whether it was crystal or powder form), and even possibly supply other PEDs for participants.

Users' attitudes towards public perception of 2,4-DNP influenced who they told about their use. Many users made the conscious decision to not divulge their drug use to their family (and often friends). Some made the distinction between "gym going" friends and "non gym-going friends". The stigma attached to 2,4-DNP use has many similarities to stereotypes associated to the use of PEDs in general. Some participants likened it to the overwhelmingly negative attitudes prevalent in society towards AAS use. Notably, some participants perceived this negative stigma as a benefit, in order to prevent any "laypeople" encountering and ingesting the drug. Most participants in this sample had experience with previous PED use, therefore considering themselves well-versed in harm reduction in similar 


\section{RUNNING HEAD: QUALITATIVE ENQUIRY OF 2,4-DINITROPHENOL USE}

contexts. In contrast, the general population was not as well educated or knowledgeable about the necessary harm reduction measures necessary with any PED. Participants made it clear they were different from the general public due to their knowledge and experience with PEDs, as well as training and diet.

An additional point to consider is the distinction even within the gym-going community between 2,4-DNP and other PEDs regarding effort. The use of 2,4-DNP has been reported to increase basal metabolic rate by $11 \%$ for every $100 \mathrm{mg}$ ingested (Grundlingh et al., 2011). The gym-going community considers 2,4-DNP a "short cut" compared to other methods of losing weight, since a rigid diet is not necessary for the drug to be effective. Conversely, AAS use is associated with pushing beyond genetic "natural" limits, a perceived necessity for certain disciplines such as bodybuilding.

Finally, the control theme underpins all aspects pertaining actual 2,4-DNP use. Participants controlled their lifestyle and other substance use while on 2,4-DNP and all but one benefitted from having experience with other PEDs. Users in this study also carefully controlled what, when and how much they revealed about their high-risk behaviour to their social groups and differentiated based on how well-informed they believed they were. Users also considered their social image when choosing not to tell friends about 2,4-DNP use. This high degree of control, coupled with respect for this very potent but highly toxic chemical suggests very clearly that users do not haphazardly take risks with 2,4-DNP. Rather, users search for information, educate themselves about the drugs and side effects, keeping a controlled lifestyle and not exceeding the amount they felt was "safe".

Participants were well aware of the risks associated to 2,4-DNP use. Many participants had a "threshold" dose which they would not bypass due to their concern about unwanted side effects. In particular, participants were concerned about death. Whilst participants seemed keen to take the risk of ingesting 2,4-DNP, the risk appears to be a "calculated" one, rather than an impulsive decision.

What is clear from the interviews is that participants would take as many measures as they felt were necessary to mitigate negative effects and yield only positive outcomes 


\section{RUNNING HEAD: QUALITATIVE ENQUIRY OF 2,4-DINITROPHENOL USE}

from 2,4-DNP use. According to the sample, negative societal effects (by not informing certain social groups of their use and maintaining anonymity) and negative physical effects (through the use of supplements or drugs, as well as through self-experimentation) could be contained and controlled. For participants, controlling and mitigating negative effects was crucial and each participant exercised their control by making certain choices within their goals and possibilities.

It can be suggested that the control element found in our cohort's narrations reflects commonalities with eating disorder symptomatology (Marzano-Parisoli, 2001). A distinction between "practical" control (in this context, controlling as many elements as possible to reduce harm from the compound) and "pathological" control (control which stems from a pathological root) is nonetheless necessary. Media reports indicate that in those suffering from eating disorders or some other pathological conditions (e.g., exercise addiction) and use 2,4-DNP, often fatally (e.g., Moore, 2017 July 27; Philby, 2013, April 23), death or serious health conditions were related to overdosing with 2,4-DNP. It remains unknown whether overdosing were due to impurity; the lack of knowledge and understanding or loss of control over the measures taken for weight loss. Further research is warranted to compare and contrast elements of "practical" control, necessary when using a highly lethal compound such as 2,4-DNP and the "pathological" control characteristic of eating disorders or exercise addiction.

\section{Comparisons with past research}

In part due to difficulties in recruiting from this population group, studies on attitudes of 2,4-DNP users have been scarce. Qualitative studies which include thematic analysis are even rarer. Petróczi et al. (2015) administered a semi-qualitative, self-reported survey to 35 2,4-DNP users. Similar to our results, the Internet was a major source for obtaining information on 2,4-DNP as well as for acquiring the actual substance. Users were aware of the health risks and made an informed choice to use the compound regardless.

A netnographic study was undertaken by McVeigh et al. (2016). This study examined online community comments from 2,4-DNP users, using thematic analysis. The results 


\section{RUNNING HEAD: QUALITATIVE ENQUIRY OF 2,4-DINITROPHENOL USE}

uncovered novel descriptive information focused on purchasing, dosages, outcomes, side effects and cycles. Individuals' attitudes towards 2,4-DNP partly mirrored our results; user groups utilised scientific studies and discussed use from a physiological perspective. Whilst McVeigh et al. (2016) compared 2,4-DNP users to novel psychoactive substance (NPS) users, we identified differences between 2,4-DNP users and AAS users.

Fimognari and Gottardi (2010) suggested a spectrum of two extremes of AAS users; the 'first extreme profile' is an individual who has a high hazard knowledge and correct risk perception - though the perceived high reward is worth the risk in their eyes. The second user is the 'second extreme profile', an individual who perceives a moderate amount of reward, yet risk and hazard perception related to AAS are limited. Fimognari \&and Gottardi (2010) suggested most users will fall between these two extremes. It is possible to extend this scale to 2,4-DNP users - the majority of our participants acknowledge the high risk and numerous potential hazards associated with using the substance. However, the high reward (high amount of fat loss in a short amount of time) is worth the calculated decision they made. Thus it is possible they would fall under the "first extreme profile".

This is also reflected in the amount of 2,4-DNP users ingest. In our and similar studies, 2,4-DNP users appear to be significantly more conservative with their doses when compared to AAS users. Parkinson and Evans (2006) found that the average dose of AAS used has increased from 1997 (where the reported dosage was $500 \mathrm{mg}$ ) to 2006 (where dosages of $1000 \mathrm{mg}$ and more were reported in the study). Whilst no studies exist to determine typical 2,4-DNP dosage, informal suggestions range between 200 and $600 \mathrm{mg}$, with potential users being advised to start off at the lower end and gradually taper up if they can do so (Petróczi et al., 2015). AAS users are mostly concerned about long term effects (Parkinson \& Evans, 2006), and side effect increases with increasing doses and number of AAS taken concurrently (Bolding, Sherr, \& Elford, 2002). Long term risks versus short term risks could potentially influence the risk and hazard perception of each user group, and this perception of acute harm could impact the dosages and methods of use in AAS compared to 2,4-DNP. 


\section{Limitations and future directions}

Procedural limitations were present within this study. One of the main limitations was sample size. Despite the interviewer being an "insider" for the community, recruitment was still challenging due to the high level of suspicion among community members. Additionally, recruitment was conducted in a short period of time (approximately four weeks). It is possible that a larger sample could be recruited over a longer period. However, it should be noted that a sufficient level of data saturation (Fusch \& Ness, 2015) was reached with our sample; similar themes were appearing repeatedly, and a point had been reached where no novel information was appearing.

Self-selection bias is an element present within this study. Many of the users in our sample were open about their drug use, as well as educated on it to some degree. However, providing representative information of 2,4-DNP users was not our intent. We aimed to provide an in-depth description of the 2,4-DNP decision-making processes. Future studies could perhaps recruit from gyms as well as other online avenues to diversify study populations, thereby opening up a new pool of participants who could discuss a different array of attitudes and experiences.

Whilst we attempted to recruit from a diverse range of participants, it is clear most participants were white Caucasian males. This might be due to the stigmatisation of female PED use; female drug use in general appears more stigmatised than male drug use (Hecksher \& Hesse, 2009; Van Olphen et al., 2009). Fewer women are willing to be open about their PED use compared to males. Scientific understanding of female PED use is much more limited compared to male PED use. Future research could potentially investigate female-specific 2,4-DNP use and decision-making.

\section{Recommendations for prevention and harm reduction policies}

It has been previously suggested in the context of AAS use that deterring people via exaggerated scare tactics and only emphasising negative effects has limited effectiveness (Petróczi, Dodge, Backhouse, \& Adesanwo, 2014). Rather, an evidence-based harm reduction approach appears to be more effective in reducing health costs (Goldberg, Bents, 


\section{RUNNING HEAD: QUALITATIVE ENQUIRY OF 2,4-DINITROPHENOL USE}

Bosworth, Trevisan, \& Elliot, 1991). Another potential direction for future research would be gathering more participants from a wider cultural pool. Currently there is little research to determine whether cultural background influences how individuals approach PED use (in particular, fat burners such as 2,4-DNP). This could be accomplished via cross-country research.

Prevention of use by presenting evidence-based information could be effective for non-users interested in initiating 2,4-DNP use. However, additional approaches should be considered for experienced 2,4-DNP users, who might not be so easily dissuaded from use. Additionally, the easy availability of the substance through the Internet makes "harmminimising" by controlling substance access challenging. It has been suggested that harm reduction in this context should focus on decreasing drug-related harm, as opposed to reducing drug use (Hunt et al., 2003). In the context of other PED users, this is a wellestablished concept, for example through the use of needle and syringe service providers (NSPs). Notably, NSP programmes also provide information on maximising the effects obtained from AAS in order to minimise the amount used (Kimergård \& McVeigh, 2014).

In the past, AAS users have been reluctant to take advice from doctors as they feel they are more educated on AAS and other PEDs than health professionals (Pope, Kanayama, lonescu-Pioggia, \& Hudson, 2004). Future research could examine if similar processes occur in a representative 2,4-DNP user cohort, determining whether similar perceptions towards medical professionals are present. Considering the findings of this study, 2,4-DNP users are pro-actively engaged in avoiding potential harms but engage in preventative measures in an isolated manner. This protective factor can be reinforced and supported by acting on possible negative attitudes towards health professionals.

Health professionals and other groups of people in contact with 2,4-DNP users should also understand that this population considers itself well informed about the risks involved. Our cohort utilised scientific studies (where possible) in order to determine dosages and educate themselves on side effects. It must also be remembered that this user 


\section{RUNNING HEAD: QUALITATIVE ENQUIRY OF 2,4-DINITROPHENOL USE}

group bases decision-making on other users' experiences, and realises that experimenting with such a substance without adequate medical supervision is inherently extremely risky.

Findings also highlight the importance of creating and maintaining community relations with the target population; the depth and richness of information gathered during our qualitative interviews brought forth many valid harm reduction recommendations from our cohort, for example informing a close friend when starting a 2,4-DNP cycle. Additionally, it can be empowering for the community to be part of policy creation. It is imperative to forge a connection with the PED-using community, and actively involve them in policy creation as much as possible. Considering the submersed nature of the PED using population and the high risks involved in using 2,4-DNP, developing effective communication strategies that better inform research, policy and preventative measures is vital. Harm reduction is an important standpoint in promoting a non-judgemental attitude and improving communication with the PED using population (DeCorte, 2001).

In a community where peer experiences are highly valued, peer-to-peer education schemes, presenting information in a non-judgemental light, and advocating the benefits of moderation in consumption whilst cautioning against excess could have beneficial outcomes for the gym-going population. Considering the dose-dependent danger associated with 2,4DNP, this moderation-based approach would be far more effective than withholding information to prevent use. Taking all of this into account, policy creation could potentially occur through well-conducted participant action research (PARs) initiatives (Baum, MacDougall, \& Smith, 2006).

\section{Conclusion}

Participants concluded that if used with caution, 2,4-DNP is highly effective and efficient as a fat loss agent. However, many also remarked upon its dangers. The main concern, in addition to adverse physical effects, was the risk of death. Most considered "respect" for the compound to be important and pivotal to reduce adversities. Internet has a powerful role and interactions with peer groups online shaped perceptions towards 2,4-DNP 


\section{RUNNING HEAD: QUALITATIVE ENQUIRY OF 2,4-DINITROPHENOL USE}

and other PEDs. Attitudes towards 2,4-DNP use are particularly polarised and complex within in-groups.

Further research on 2,4-DNP use within gym-goers is warranted. Understanding users' motives and decision-making processes is crucial to develop better interventions and policies. It is also a priority to adopt a non-judgemental approach and avoid further marginalisation of 2,4-DNP users. Instead, using their experiences to devise prevention, education and valid harm-reduction strategies could be beneficial to public health initiatives.

\section{Conflict of interest}

This research was supported by the Hampshire County Council Scientific Services. We are thankful to our colleague, Jorge Ocampo, for co-creating the interview questions and the codebook for the analysis.

We are also grateful to our participants who put their trust in our research, and for their willingness to disclose their personal experiences.

There are no conflicts of interest.

\section{References}

Abrahin O.S.C., de Sousa E.C. and Santos A.M., Prevalence of the use of anabolicandrogenic steroids in Brazil: A systematic review, Substance Use \& Misuse 49 (9), 2014, 1156-1162.

Allen T.D. and Benson V.M., Late development of cataract following use of dinitrophenol about a year before, Journal of the American Medical Association 105 (10), 1935, 795-795.

Barratt M.J., Discussing illicit drugs in public internet forums: Visibility, stigma, and pseudonymity, In: Proceedings of the 5th international conference on communities and technologie

ACM2011, 159-168, [June].

Baum F., MacDougall C. and Smith D., Participatory action research, Journal of Epidemiology and Community Health 60 (10), 2006, 854-857. 
Biernacki P. and Waldorf D., Snowball sampling: Problems and techniques of chain referral sampling, Sociological Methods \& Research 10 (2), 1981, 141-163.

Boardman W.W., Rapidly developing cataract after dinitrophenol, Journal of the American Medical Association 105 (2), 1935, [108-108].

Bolding G., Sherr L. and Elford J., Use of anabolic steroids and associated health risks among gay men attending London gyms, Addiction 97 (2), 2002, 195-203.

Braun V. and Clarke V., Using thematic analysis in psychology, Qualitative Research in Psychology 3 (2), 2006, 77-101.

DNP, Warnings issued over deadly DNP 'diet drug', 2013, [Retrieved from] http://www.nhs.uk/news/2013/09September/Pages/Warnings-issued-over-deadly-DNP-diet-

drug.aspx.

DNP, New warnings issued over deadly DNP 'diet drug', 2014, [Retrieved from]

http://www.nhs.uk/news/2014/01 January/Pages/New-warnings-issued-over-deadly-DNPdietdrug.aspx.

DeCorte T., Quality control by cocaine users: Underdeveloped harm reduction strategies?, European Addiction Research 7 (4), 2001, 161-175.

Evans N.A., Current concepts in anabolic-androgenic steroids, The American Journal of Sports Medicine 32 (2), 2004, 534-542.

FSA action over DNP 'fat burner substances', 2013, [Retrieved from]

http://webarchive.nationalarchives.gov.uk/+/http://www.food.gov.uk/newsupdates/news/2013/57 72/dnp\#.UjRTMakoyh .

Fimognari L. and Gottardi M., Risk, hazard and reward perception concerning anabolic androgenic steroids (AAS) intake (Doctoral dissertation), 2010, [Retrieved from] https://core.ac.uk/download/pdf/12518542.pdf.

Fusch P.I. and Ness L.R., Are we there yet? Data saturation in qualitative research, The Qualitative Report 20 (9), 2015,1408-1416, [Retrieved from: http://nsuworks.nova.edu/tqr/vol20/iss9/3 . Gergen M.M. and Gergen K.J., Qualitative inquiry: Tensions and transformations, Handbook of Qualitative Research 2, 2000, 1025-1046, 
[Retrieved from] http://salihabava.com/learning/wpcontent/uploads/2011/08/Gergens-

2003Qualitative Inquiry Tensions and Transformations.pdf.

Goldberg L., Bents R., Bosworth E., Trevisan L. and Elliot D.L., Anabolic steroid education and adolescents: Do scare tactics work?, Pediatrics 87 (3), 1991, 283-286.

Goldgof M., Xiao C., Chanturiya T., Jou W., Gavrilova O. and Reitman M.L., The chemical uncoupler 2, 4-dinitrophenol (DNP) protects against dietinduced obesity and improves energy homeostasis in mice at thermoneutrality, Journal of Biological Chemistry 289 (28), 2014, $19341-19350$.

Gonzalez A., McLachlan S. and Keaney F., Anabolic steroid misuse: How much should we know?, International Journal of Psychiatry In Clinical Practice 5 (3), 2001, 159-167.

Grundlingh J., Dargan P.I., El-Zanfaly M. and Wood D.M., 2, 4-dinitrophenol (DNP): a weightloss agent with significant acute toxicity and risk of death, Journal of Medical Toxicology 7 (3), 2011, 205-212.

Hardgrove M. and Stem N., Dinitrophenol: A review of the literature, Industrial Medicine 7, 1938, 9-17.

Harris M.O. and Cocoran J.J., Toxicological profile for dinitrophenols, 1995, Agency for Toxic Substances and Disease Registry; Atlanta, [Retrieved from] https://www.atsdr.cdc.gov/ToxProfiles/tp64.pdf. Health and Social Care Information Centre, Hospital statistics, admitted patient care, England 2012-2013, 2013, [Retrieved from] http://www.hscic.gov.uk/catalogue/PUB1256612.

Hecksher D. and Hesse M., Women and substance use disorders, Mens Sana Monographs 7 (1), 2009, 50-62. 
Hitti E.A., Melki J.P. and Mufarrij A.J., The prevalence and determinants of anabolic steroid use among fitness centre attendees in Lebanon, International SportMed Journal 15 (4), 2014, 391-401.

Horner W.D., Dinitrophenol and its relation to formation of cataracts, Archives of Ophthalmology 27, 1942, 1097-1121.

Hoxha B. and Petróczi A., Playing with fire? Factors influencing risk willingness with the unlicensed fat burner drug 2, 4 Dinitrophenol (DNP) in young adults, Public Health 129 (11), 2015, 1519-152.

Hunt N., Ashton M., Lenton S., Mitcheson L., Nelles B. and Stimson G., A review of the evidencebase for harm reduction approaches to drug use, 2003, Forward Thinking on Drugs; London,[Retrieved from:] http://neilhunt.org/pdf/2003-evidence-base-for-hr-hunt-et-al.pdf. Jeukendrup A.E. and Randell R., Fat burners: Nutrition supplements that increase fat metabolism, Obesity Reviews 12 (10), 2011, 841-851.

Kamour A., George N., Gwynnette D., Cooper G., Lupton D., Eddleston M., ... Thomas S.H.L., Increasing frequency of severe clinical toxicity after use of 2, 4-dinitrophenol in the UK: A report from the National Poisons Information Service, Emergency Medicine Journal 32 (5), 2015, 383-386.

Khullar N., Scull N.C., Deeny M.C. and Hamdan E., Prevalence and predictors of anabolicandrogenic steroid use among gym users in Kuwait: A preliminary study, International Journal of Men's Health 15 (2), 2016, 144.

Kicman A.T., Pharmacology of anabolic steroids, British Journal of Pharmacology 154 (3), 2008, 502-521.

Kimergård A. and McVeigh J., Variability and dilemmas in harm reduction for anabolic steroid users in the UK: A multi area interview study, Harm Reduction Journal 11 (1), 2014, 19.

Kniskern P.W., Cataracts following dinitrophenol, Journal of the American Medical Association 105 (10), 1935, 794-795.

Lazar N.K., Cataract following the use of dinitrophenol, Journal of the American Medical Association 105 (10), 1935, 794794. 
Lazuras L., Barkoukis V., Loukovitis A., Brand R., Hudson A., Mallia L., ... Zelli A., I want it all, and I want it now: Lifetime prevalence and reasons for using and abstaining from controlled performance and appearance enhancing substances (PAES) among young exercisers and amateur athletes in five European countries, Frontiers in Psychology 8, 2017, 717.

Marzano-Parisoli M., The contemporary construction of a perfect body image: Bodybuilding, exercise addiction, and eating disorders, Quest 53 (2), 2001, 216-230.

McVeigh J., Germain J. and Van Hout M.C., 2, 4-Dinitrophenol, the inferno drug: A netnographic study of user experiences in the quest for leanness, Journal of Substance Use 2016, 1-8.

Meinhardt U., Nelson A.E., Hansen J.L., Birzniece V., Clifford D., Leung K.C. and Ho K.K., Effects of growth hormone on body composition and physical performance in recreational athletes a randomized trial, Annals of Internal Medicine 152 (9), 2010, 568-577.

Molero Y., Bakshi A.S. and Gripenberg J., Illicit drug use among gym-goers: A cross-sectional study of gym-goers in Sweden, Sports Medicine Open 3 (1), 2017, 31.

Moore C., Family of young woman, 21, who died after taking an overdose of killer diet pills blast the failures of 'overwhelmed' hospital for failing to treat her sooner, 2017, Retrieved September 21 from: http://www.dailymail.co.uk/news/article4735942/Young-woman-died-taking-dietpills.html.

Morris S., Woman died after accidental overdose of highly toxic diet pills, 2015, Retrieved September 18, 2017, from https://www.theguardian.com/society/2015/jul/23/woman-diedaccidental-overdose-highly-toxic-diet-pills-eloise-parry.

Nakhaee M.R., Pakravan F. and Nakhaee N., Prevalence of use of anabolic steroids by bodybuilders using three methods in a city of Iran, Addiction \& Health 5 (3-4), 2013, 77-82. Parascandola J., Dinitrophenol and bioenergetics: An historical perspective, Molecular and Cellular Biochemistry 5 (1), 1974, 69-77.

Parkinson A.B. and Evans N.A., Anabolic androgenic steroids: A survey of 500 users?, Medicine \& Science in Sports \& Exercise 38 (4), 2006, 644-651. 
Perry P.J., Lund B.C., Deninger M.J., Kutscher E.C. and Schneider J., Anabolic bsteroid use in weightlifters and bodybuilders: An internet survey of drug utilization, Clinical Journal of Sport Medicine 15 (5), 2005, 326-330.

Petróczi A., Dodge T., Backhouse S.H. and Adesanwo C., Review of the literature on negative health risks based interventions to guide anabolic steroid misuse prevention, Performance Enhancement \& Health 3 (1), 2014, 31-44.

Petróczi A., Ocampo J.A.V., Shah I., Jenkinson C., New R., James R.A., .. Naughton D.P., Russian roulette with unlicensed fat burner drug 2, 4-dinitrophenol (DNP): evidence from a multidisciplinary study of the internet, bodybuilding supplements and DNP users, Substance Abuse Treatment, Prevention, and Policy 10 (39), 2015.

Philby C., Death of medical student Sarah Houston after taking banned slimming drug Dinitrophenol highlights dangers of buying pills online, warns Government, 2013, Retrieved September 18, 2017, from http://www.independent.co.uk/news/uk/homenews/death-of-medical-student-sarah-houston-after-taking-banned-slimming-drugdinitrophenol-highlights-8584597.html.

Phillips L. and Singer M.A., Peripheral neuropathy due to dinitrophenol used for weight loss:

Something old, something new, Neurology 80 (8), 2013, 773-774.

Pope H.G., Kanayama G., Ionescu-Pioggia M. and Hudson J.I., Anabolic steroid users' attitudes towards physicians, Addiction 99 (9), 2004, 1189-1194.

Reardon C.L. and Creado S., Drug abuse in athletes, Substance Abuse and Rehabilitation 2014 (5), 2014, 95-105.

Sagoe D., Andreassen C.S. and Pallesen S., The aetiology and trajectory of anabolic androgenic steroid use initiation: A systematic review and synthesis of qualitative research, Substance Abuse Treatment, Prevention, and Policy 9, 2014, 27.

Sagoe D., Molde H., Andreassen C.S., Torsheim T. and Pallesen S., The global epidemiology of anabolic-androgenic steroid use: A meta-analysis and meta regression analysis, Annals of Epidemiology 24 (5), 2014, 383-398. 
Sepehri G., Mousavi Fard M. and Sepehri E., Frequency of anabolic steroids abuse in bodybuilder athletes in Kerman city, Addiction \& Health 1 (1), 2009, 25-29.

Simon P., Striegel H., Aust F., Dietz K. and Ulrich R., Doping in fitness sports: Estimated number of unreported cases and individual probability of doping?, Addiction 101 (11), 2006, 16401644.

Striegel H., Simon P., Frisch S., Roecker K., Dietz K., Dickhuth H.H. and Ulrich R., Anabolic ergogenic substance users in fitness-sports: A distinct group supported by the health care system?, Drug and Alcohol Dependence 8 (1), 2006, 11-19.

Stubbe J.H., Chorus A.M., Frank L.E., Hon O. and Heijden P.G., Prevalence of use of performance enhancing drugs by fitness centre members?, Drug Testing and Analysis 6 (5), 2014, 434438.

Tainter M.L., Stockton A.B. and Cutting W.C., Dinitrophenol in the treatment of obesity: Final report, Journal of the American Medical Association 105 (5), 1935, 332-337.

Van Olphen J., Eliason M.J., Freudenberg N. and Barnes M., Nowhere to go: How stigma limits the options of female drug users after release from jail, Substance Abuse Treatment Prevention, and Policy 4 (1), 2009, 10.

Wallace K.B. and Starkov A.A., Mitochondrial targets of drug toxicity, Annual Review of Pharmacology and Toxicology 40 (1), 2000, 353-388.

Weber R.P., Basic content analysis, 1990, Sage Publications; Newbury Park, CA. 


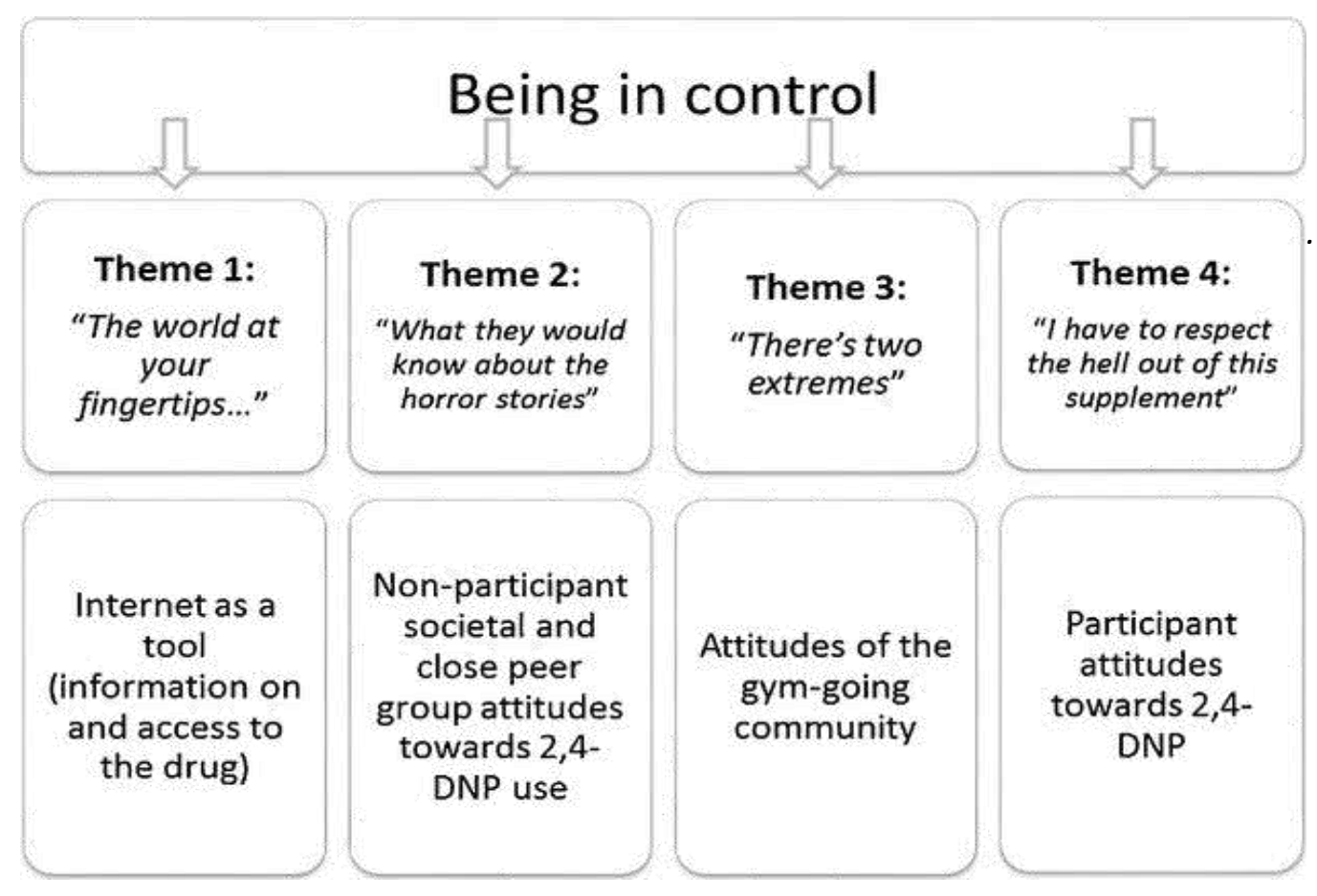

Figure 1. Visual presentation of emergent themes within this study 


\section{APPENDICES}

\section{Appendix 1: Interview guide}

Thank you for taking part in this study. I am going to ask you some questions regarding your experience with DNP. I will audio record your answers. My research group is interested in understanding why people use DNP and finding out how we can protect your health and wellbeing and minimize harm. I value your experience and will not judge you in any way. I also guarantee complete confidentiality. Any private information you provide (names, places, etc.) will be deleted from the transcription. The information we gather may be used to produce a scientific paper. Parts of your answers may be used as examples within the manuscript. I want to clarify though that the information we gather will be interpreted as a whole and we are not interested in analysing you individually. We guarantee that your identity will be kept completely anonymous and will be safeguarded. Please confirm that you consent.

1. When did you start training and what were your reason[s] for starting?' 'Do those reasons still motivate you to train or have your goals changed?

2. What PED do you currently use?

3. When did you start using PEDs? What were your reasons for doing so?

4. How did you get to know about DNP?

5. Where did you learn how to use it?

6. What was the main reason you started using DNP?

7. Can you describe the first time you used DNP?

8. Have you had any previous experience with any other appearance enhancing drugs?

9. Were you concerned about any repercussions that could have risen?

10. How did you assure that the pills were actually DNP?

11. Were you aware of the other uses of DNP?

12. What did you want to gain from DNP?

13. What was the purpose of adding DNP as a supplement to your regime?

14. How did DNP change your physique?

15. How did you plan your DNP cycles? 
16. Can you describe the side effects arising from the beginning, during and after of the DNP cycle?

17. When did side effects first appear?

18. Have you researched about any of DNP side effects?

19. Were there any changes in your mode of consumption since you started using DNP?

20. Were you using any other recreational drugs, steroids or supplements while on DNP?

21. How did you get a hold of DNP?

22. How much would an average DNP cycle cost?

23. Can you describe what the intake limit of your body is?

24. How does your bodybuilding community react towards you using DNP?

25. What do untrained people think about you using DNP?

26. Were friends and family aware of your use of DNP?

27. What is your opinion towards DNP? (Have/would you recommend it to anybody?)

28. What misconception have you found that people have about DNP?

*Remember to keep the discussion as open as possible. Don't be afraid to ask many "whys".

\section{Variables}

Motivation

Reasons

Expectation

Side effects

Effects

Use of other drugs

Knowledge of DNP

Peers

Purchase 
Appendix 2: Codebook for coding of transcripts

\section{Motivations}

"Reasons for using DNP; my personal motivations"

1. Losing weight

2. To compete

3. "other" motivations

4. Expectations of positive effects (pros)

"Pre-conceived notions regarding the advantages of using DNP; information from external sources"

5. Expectations of negative effects (cons)

"Pre-conceived notions regarding the disadvantages of using DNP; information from external sources"

- Side-effects

"Detrimental effects of DNP"

6. Physiological side-effects

7. Mental side-effects

8. Impact on daily life

- Duration of side-effects (of DNP use)

9. Side-effects at the beginning

10. Side-effects during

11. Side-effects after

- Effects

"Positive outcomes related to DNP use"

12. Aesthetic effects

13. Losing weight

- DNP cycle details (to analyse post-hoc the "deviations from plan")

14. Type used

15. Type of training

16. Type of diet

17. Time of day

18. Duration of cycle

19. Dosage

- Use of other drugs besides DNP

20. Drugs to have fun 
21. Drugs to help daily function

22. Other PEDs

23. Other uses of DNP

"Anything that does

n't involve fat burning"

24. Sources of information

- Attitudes of social networks

"Opinions of DNP use on the part of family, friends and community"

25 . Views of the gym goers community

26. Opinions of friends/family

27. Attitudes of society

28. Misconceptions of society

29. Opinions towards DNP

"Personal opinion after experiencing DNP"

30. Would you recommend it?

- Purchasing DNP

"Information related to buying DNP"

31. Cost of DNP

32. Purchase from internet

33. Purchase in person

34. Accessibility

35. Trust in the product

- General Information

"Athletic history of participants"

36. Current training

37. Athletic background 